\title{
O Conceito de Velocidade Aplicado em Corpos Rígidos em Rotação: mesmas concepções alternativas, variadas interpretações
}

\section{The Concept of Speed Applied to Rigid Bodies in Rotation: Same alternative conceptions, varied interpretations}

\author{
Osmar Henrique Moura da Silva ${ }^{1}$;Carlos Eduardo Laburú; Marcelo Alves Barros ${ }^{3}$
}

Resumo

Este trabalho apresenta uma investigação em que algumas concepções alternativas são a origem e o desencadeamento de variadas interpretações. Para isso, foram propostos a alunos do ensino médio a resolução de determinados problemas que envolviam corpos rígidos em rotação constante. Estes problemas deveriam ser analisados dentro da perspectiva do conceito de velocidade, previamente conhecido dos alunos, mas abandonado pelas explicações geradas pelas concepções alternativas.

Palavras-chave: Velocidade Linear. Concepções Alternativas. Interpretação. Corpos Rígidos. Rotação.

\begin{abstract}
This work presents an investigation where some alternative conceptions are the origin and the processing of varied interpretations. As for that, it was proposed to high school students the resolution of certain problems that involved rigid bodies in constant rotation. These problems should be analysed within the perspective of the speed concept, which was previously known by the students, but abandoned by the explanations generated by the alternative conceptions.
\end{abstract}

Key words: Linear Speed. Alternative Conceptions. Interpretation. Rigid Bodies. Rotation.

\section{Introdução}

Este trabalho faz uma análise do uso de certas concepções alternativas, empregadas por alunos do ensino médio, com o objetivo de mostrar as fontes e interpretações do emprego dessas concepções. Tais concepções aparecem com vigor, em virtude da tentativa dos estudantes em aplicar o conceito de velocidade linear nos corpos rígidos em rotação. Os alunos investigados já detinham a compreensão desse conceito, pois o aplicavam com maestria suficiente em situações de pontos materiais e problemas mais tradicionais. O surgimento dessas concepções se dá no momento em que se pede aos alunos que analisem um grupo de quatro problemas, conforme anexo, e

\footnotetext{
1 Departamento de Física, Universidade Estadual de Londrina. CEP 86051-970, Cx. P. 6001, Londrina, PR. Fone: $3371-4163$. Email: osmarh@uel.br.

2 Departamento de Física, Universidade Estadual de Londrina. CEP 6001, 86051-970, Londrina, PR, Brasil Email: laburu@uel.br e Email: osmarh@uel.br.

3 Departamento de Física, Universidade Estadual de Maringá. CEP 87020-900, Maringá, PR, Brasil. Email: mbarros@dfi.uem.br.
} 
que foram basicamente inspirados no trabalho de Silva (1990). Como se verá, esses problemas disparam num número significativo de estudantes concepções intuitivas que bloqueiam o emprego correto do conceito de velocidade.

O programa de pesquisa em concepções alternativas remonta aos finais dos anos setenta, mas foi na década seguinte que se deu uma explosão de trabalhos publicados nessa direção, passando esse programa a ser simplesmente rotulado de ACM (Alternative Conceptions Movement) por Gilbert e Swif (1985). Esse movimento buscou as idéias intuitivas de crianças e adolescentes, nas mais diversas áreas e assuntos científicos (PFUNDT; DUIT, 1991; CARMICHAEL et al., 1990).

Apesar de nos anos noventa ainda ter havido um substancial número de pesquisas na linha ACM, que continuavam a examinar e meramente descrever conceitos alternativos de estudantes, já um editor de uma importante revista da área (Duschl e Science Education) insistia, em 1994, que era tempo de avançar na direção de investigações ou análises que ajudassem a promover um entendimento, tanto das fontes dessas concepções, como das estratégias envolvidas na sua utilização.

É nesse sentido que este trabalho pretende contribuir na medida em que vai procurar fazer uma análise junto a conhecidas concepções alternativas, procurando interpretar e alertar os entendimentos surgidos dos raciocínios dos alunos a partir tanto dessas concepções, como de suas estratégias utilizadas. Tais preocupações não foram objeto de nenhum estudo até agora.

\section{Metodologia}

A amostra desta pesquisa foi obtida de duas turmas do ensino médio, período diurno, com um total de sessenta estudantes. Uma do primeiro ano de um colégio público na região central da cidade de Londrina e a outra de alunos do segundo ano do colégio de Aplicação da USP. Dentro dos objetivos deste trabalho, não houve interesse em identificar os colégios a que pertenciam os alunos, portanto, os exemplos apresentados na próxima seção não permitem saber o colégio de um aluno específico.

As idéias dos estudantes foram obtidas durante a análise dos quatro problemas do anexo, feita em pequenos grupos de três a cinco alunos cada.

Como o objetivo do trabalho é investigar as estratégias e as interpretações destas a partir das concepções alternativas, excluíram-se as respostas corretas dos alunos, por não serem relevantes dentro desse propósito. Da mesma forma, abaixo estão destacadas apenas as falas mais representativas obtidas.

As respostas foram registradas por videogravação e posteriormente transcritas para serem analisadas. Antes do início das discussões, os alunos foram alertados para trabalhar com a definição de velocidade linear na comparação das velocidades dos pontos A e B, em cada questão. Com isso, tentou-se evitar o desvio do assunto e situar os raciocínios dos alunos nas questões. Todas as questões podem ser respondidas qualitativamente a partir da correta articulação das variáveis pertencentes ao conceito escolarizado de velocidade escalar média, ou seja, como variação do espaço pelo intervalo de tempo (V=DS/DT).

A atividade proporcionada pela reunião em grupo oportunizou a criação de um espaço para que os alunos levantassem suas próprias idéias, as debatessem e criticassem, entre si. As questões geraram conflitos sócio-cognitivos (Laborde 1996: 39), originando idéias que variaram entre uma noção intuitiva de velocidade global, próxima a uma noção de velocidade angular, e o conceito de velocidade linear aprendido (SILVA 1990; DION, 1992).

No que se refere às particularidades da construção das questões, é preciso apontar que a primeira e a terceira apresentam características do movimento de um sólido em rotação. Por contraste, a segunda questão trata do movimento de partículas isoladas, representadas por móveis que percorrem, colateralmente, pistas circulares concêntricas. 
Quanto à quarta questão, também por contraste com as questões antecedentes, procurou-se caracterizála pela distinção entre diferentes rotações dadas pelas roldanas, com a possibilidade de se encontrar velocidades lineares semelhantes, dada pela correia de transmissão.

As transcrições das falas dos alunos estão descritas na íntegra, portanto, sem correções gramaticais. Porém, suprimiram-se das mesmas palavras ou sentenças, com pouco ou nenhum interesse para o objetivo do trabalho. Entre parênteses, aparecem comentários do observador com a intenção de dar maior clareza às falas. Os alunos ou alunas identificados aparecem com nomes fictícios.

\section{Interpretações das concepções alternativas}

O primeiro comentário refere-se à questão dois, que propunha salientar móveis solados, em trajetórias específicas, e nela aconteceu de não aparecer problemas para sua solução, pois todos os alunos a responderam de forma correta. Isto foi importante para observarmos que os alunos estavam de posse do conceito correto de velocidade ensinado ${ }^{4}$.

Todavia, para as questões restantes, foi possível identificar vários alunos abandonando o conceito de velocidade previamente dominado em função da ação de duas concepções alternativas básicas, inclusive uma delas bem disseminada na literatura. As duas concepções foram utilizadas pelos estudantes de formas variadas e conduziram a diversas interpretações que prejudicaram a aplicação correta do conceito de velocidade.

Podemos começar pela constatação da concepção intuitiva que associa a noção de velocidade à força (VIENNOT, 1979), aplicada para entender o corpo rígido em rotação, sendo utilizada para justificar diversas idéias. Vejamos o caso em que essa concepção é usada para explicar a incorreta resposta da maior velocidade do ponto A em relação ao ponto B:
Adalberto - Questão 3 - (mantém uma caneta e gesticula com a mesma) - A velocidade do A (ponto A) é maior que a do B (ponto B). Você pega um cone (exemplificando com a caneta) e você começa daqui (extremidade representada pela ponta do cone), a força começou aqui e, daqui, vai para baixo. Então aqui (ponto A), já começa mais rápido (justificando a maior velocidade para o ponto A). Pensei no caso da bicicleta (associando a Questão 3 e 4). A gente começa pedalando daqui (roldana menor), e a força começa aqui (na roldana menor, onde se pedala) para depois passar para lá. Então, a velocidade de B (ponto B) é maior do que a de A (ponto A).

Ana - Questão 3 - (segurando uma caneta pela extremidade para exemplificar o cone). A gente roda (a caneta, com os dedos) e a gente vê que vai tudo igual (mostrando que os pontos A e B possuem a mesma velocidade), mas a gente vê que o ponto $\mathrm{A}$ roda mais rápido (maior velocidade) que o ponto $B$, porque quando a gente gira (a caneta) o ponto A gira mais rápido. $O$ ponto A começa primeiro, porque até chegar (a força) ao ponto $B[\ldots]$, ele começa primeiro (ponto A). Como o A está em cima (próximo da ponta do cone) ele gira mais rápido (possui maior velocidade). A gente vê que gira tudo, só que ele (ponto A) gira mais rápido (maior velocidade).

Por esses exemplos complementares, vê-se que há a avaliação incorreta de uma velocidade maior para um ponto próximo (ponto A) da extremidade do cone em rotação do que para outros pontos mais distantes (ponto B). De acordo com a leitura dos alunos, existe a compreensão de que uma força aplicada na extremidade (ponto A) é repassada para os pontos mais afastados (ponto $B$ ). $O$ raciocínio que se encontra por detrás deste tipo de resposta é a existência de um aumento gradual das velocidades dos pontos, a partir da extremidade superior do cone. Isso ocorre devido a uma força imaginária aplicada ao corpo, e necessária para mantê-lo em movimento, ir sendo transferida para outros locais do corpo rígido. Portanto, a estratégia utilizada é a seguinte: parte-se da concepção alternativa geral de força proporcional à velocidade e de uma idéia de transmissão não- 
instantânea de força pelos corpos extensos, para justificar as diferentes velocidades nos diferentes pontos do corpo. Também se imagina uma força aplicada na ponta do cone para mantê-lo em movimento.

É possível observar a robustez determinante dessa concepção e sua influência no raciocínio, na fala de Carlos, abaixo. Apesar de reconhecer que o percurso do ponto $\mathrm{B}$ no cone é maior do que o do ponto $\mathrm{A}$, e que o tempo de percurso é o mesmo, portanto, estando com os elementos necessários para admitir a maior velocidade de $\mathrm{B}$ em relação à de $\mathrm{A}$, Carlos prefere abandonar o conceito de velocidade aprendido pelo vínculo impróprio entre velocidade e força. A impropriedade aparece quando o aluno imagina que uma pessoa arremessada de uma região próxima da ponta do cone possui maior força e, consequentemente, maior velocidade:

Carlos - Questão 3 - A velocidade do A (ponto A) é maior que a do $B$ (ponto B). O B tem um espaço maior, o A tem um espaço menor mas, o $A$ tem maior velocidade que o $B$, ele roda mais rápido, porque está mais perto da ponta. Chegam no mesmo tempo. Por exemplo, se tem um cone girando e eu estou embaixo (local do ponto B) $e$ você em cima (local do ponto A) e, se o cone parar, quem vai ser arremessado mais longe é quem está em cima. Quem vai ser arremessado com mais força é quem está em cima, não quem está embaixo. Por isso (por ter maior força) que o $A$ (ponto A) tem maior velocidade que o $B$ (ponto $\mathrm{B}$ ). Questão 4 - A velocidade de A não é igual à velocidade de $B$, porque se aqui é menor (roldana menor) ele (ponto $\mathrm{B}$ ) passa mais rápido (maior velocidade). (Portanto) A velocidade de A tem que ser menor que a velocidade de B. Nesse caso como o espaço do $B$ (na roldana menor, onde passará o ponto $\mathrm{B})$ é menor, ele passa mais rápido. A velocidade de B é maior que a de A. O B tem maior velocidade que o A porque aqui (na roldana menor) tem mais força, por exemplo, se fosse um pedal (gesticula com as mãos, referindo-se a um pedal de bicicleta).
Apresenta Carlos, então, firme entendimento baseado na crença de que o ponto que circula numa região mais próxima do eixo de rotação tem maior velocidade, portanto, maior força. Vê-se, ainda, que o aluno faz a comparação com o tamanho das roldanas para analisar, comparativamente, as velocidades entre os pontos A e B, na quarta questão. Percebe-se aí uma nítida confusão entre a noção de giro - velocidade angular - das roldanas e as velocidades dos pontos A e B da própria correia, o que faz com que a concepção alternativa utilizada na terceira questão pudesse ser novamente aplicada, associando rotação maior a maior força, por conseqüência, à maior velocidade.

Como dissemos, diferentes respostas são produzidas na medida em que distintos pontos de vista são elaborados a partir da concepção central "força proporcional à velocidade”. Enquanto estrutura nuclear de pensamento, essa concepção é articulada de forma a dar coerentes linhas de raciocínio, possibilitando soluções distintas para as velocidades entre os pontos A e B. Dessa forma, diversamente dos pensamentos anteriores, essa concepção também pode vir a determinar a impossibilidade de haver várias velocidades em locais distintos de um mesmo corpo extenso em rotação, como se verifica pela fala de Antônia e Carol:

Antônia - Questão 3 - (o aluno tenta argumentar contra a idéia de que as velocidades no cone possam ser diferentes) Meu, como a velocidade de uma caneta (serve-se de uma caneta e a manipula na frente dos colegas a fim de relacioná-la à segunda questão do cone) dessa pode ser maior no rabo do que na ponta, se a caneta é a mesma? (a caneta é girada, mantendo uma extremidade fixa). Então, por que a ponta é que ganha velocidade? [...] A força (da pessoa) que tá girando assim (caneta em pé) é a mesma (que) tá girando assim (caneta deitada). (A estudante entende que se a força aplicada à caneta é a mesma quando ela está em pé, o que resulta em movimentos semelhantes nas pontas de cima e de baixo da caneta, o mesmo deveria acontecer com a caneta deitada, pois, novamente, 
se está aplicando uma única força). [...] (respondendo para Ana que argumenta serem as velocidades diferentes). Então, mas o que acontece, a ponta tá ganhando velocidade, não dá pra entender! A força que tá girando é a mesma, é o mesmo dedinho (dedo que está segurando a caneta). Não, você está pondo mais força no ponto do que no rabo? Não dá pra entender! A velocidade não vai vir do nada. Isso aqui (caneta) não vai sair andando sozinho. Você, você põe velocidade no negócio, você põe? Você põe força pra girar, velocidade.

Carol - Questão 3 - É um corpo só tomando impulso de apenas uma força. Uma força dando impulso para um corpo e dois pontos marcados. E os dois pontos têm a mesma velocidade, pois os dois pontos estão dentro de um só corpo, que só tem uma velocidade. Dentro de um corpo você vai ter duas velocidades diferentes? Dois pontos quaisquer marcados nele, mesma velocidade. [...] Eu acho assim. Pra criar uma situação semelhante no segundo e no terceiro problema teria que fazer a pista andar no lugar do carrinho (pontos A e B na questão 2). Se a pista tivesse andando com os dois carrinhos em cima, aí uma mesma pista poderia ter uma semelhança.

Para as duas estudantes, partir da idéia da aplicação de uma mesma e única força ("é o mesmo dedinho", em Antônia) no cone para mantê-lo girando, implica inferir a existência de uma velocidade exclusiva em toda a extensão do corpo. Assim, a mesma concepção "força proporcional à velocidade” é, neste caso, usada de maneira diferente dos exemplos antecedentes, pois agora se concebe que a força aplicada ao corpo rígido é transmitida de forma única para todo o corpo, ou como diz Carol "É um corpo só tomando impulso de apenas uma força”.

No entanto, a idéia da impossibilidade de várias velocidades no corpo extenso em rotação também pode surgir de uma segunda e mais simples intuição que envolve a necessidade de uma velocidade global (DION, 1992), resultado de uma noção primitiva de velocidade angular (SILVA, 1990). Esta intuição parece estar sustentada na idéia de um corpo rígido em rotação, como em translação, ter suas partes submetidas ao mesmo tipo de movimento, o que o manteria unido, pois, na possibilidade de suas partes se locomoverem com distintas velocidades, o corpo despedaçar-se-ia, ou como diz Angélica, no exemplo abaixo, o objeto ficaria visualmente distorcido, "embaçado". De forma semelhante, os exemplos de Bruno ("[...] porque não é o ponto A e B que roda, é o CD que roda”.) e Carol (“[...] os dois pontos têm a mesma velocidade, pois os dois pontos estão dentro de um só corpo, que só tem uma velocidade”), na seqüência, permite-nos presenciar o quão geral é essa idéia, quando admite velocidades distintas para objetos individuais, todavia, negando-a na situação de corpos rígidos.

Angélica - Questão 3 - (concordando com a idéia da velocidade dos pontos A e B serem iguais) Com duas velocidades; a parte de cima girando mais rápido do que a de baixo. É um cone só! Sabe quando uma coisa, quando começa a girar e começa a ficar (a sua percepção) embaçado (por causa do movimento rápido). Tem que imaginar! A parte de cima do cone fica mais embaçado do que a de baixo ou ao contrário. Quando a coisa tá girando muito rápido embaça a visão. A parte de baixo nesse objeto [...](é cortada por outra aluna). Daí você vê inteirinho torto.

Bruno - Questão 1 - É igual (mesma velocidade dos pontos $\mathrm{A}$ e B) porque não é o ponto $\mathrm{A}$ e $\mathrm{B}$ que roda, é o $C D$ que roda. Eles rodam ao mesmo tempo, juntos. Porque se existisse velocidade diferente (dos pontos A e B), esse daqui (ponto B) iria rodar muito mais (ou seja, o ponto B completaria uma volta antes do ponto A). (questão 3) - É o mesmo caso do CD. Aqui é o cone que roda e não os pontos A e B. Os dois (pontos A e B) rodam ao mesmo tempo e a velocidade dos pontos (A e B) são iguais. - (questão 2) - A velocidade do $B$ (ponto B) é maior porque os dois estão lado a lado (separados, percorrendo trajetórias curvas) e a distância (pista) do B (ponto B) é maior. Se eles estão lado a lado, a velocidade do (ponto) B tem que ser maior, para andar maior distância. 
Em relação à questão dois, como já dissemos, é de se destacar que Bruno, particularmente, aplica coerentemente o conceito de velocidade em objetos distintos em pistas separadas, mas desvia-se da idéia correta quando o corpo é extenso. Logo, a noção cinemática de velocidade aprendida e convenientemente considerada para móveis distintos ou para corpos extensos em translação fica prejudicada, quando nestes últimos estão envolvidas rotações. Esses exemplos deixam evidentes para vários alunos que os corpos rígidos girantes, no que se refere à análise cinemática, parecem pertencer à outra categoria. Essa categoria os distingue dos móveis que só sofrem translação, argumento que pode ser corroborado por Cássio, abaixo: “No cone é diferente daquele círculo", quando compara os móveis independentes da questão dois, com o cone da questão três.

Além dessas formas explicativas, asseguradas e derivadas da noção intuitiva de velocidade global, outra forma imaginativa gerada por esta noção, que poderíamos denominar de problema do sistema de eferência, é encontrada nas falas de Evandro e Cássio:

Evandro - Questão 3 - A velocidade dos dois (pontos A e B) são iguais. Olha, a velocidade é a mesma, mas só que o $B$ (ponto B) percorre um espaço maior que o A. A velocidade pode ser a mesma (para os pontos A e B), mas o espaço (é) que muda. O espaço (dos pontos) pode ser um maior que o outro, mas a velocidade (dos pontos) é a mesma. É o cone que tá girando, tipo assim, os dois pontos tão parado porque o cone é um só. Os pontos (A e B) tão parado em velocidade igual. (questão 1) - Não são os pontos (A e B) que rodam, é o CD. Eles (os pontos A e B) vão rodar sempre no mesmo lugar. (Os pontos A e B) Vão estar sempre com a mesma velocidade e os dois chegam juntos, chegando no mesmo tempo.

Cássio - Questão 3 - Os pontos, se for fixar no cone, eles estão parados. Eles não estão nem com velocidade. Aí (questão 3) pergunta se eles vão percorrer. Aí eles nem vão percorrer, eles vão ficar sempre no mesmo lugar. O que vai mexer é o cone. Eles (os pontos) vão ter velocidades iguais. Eles não tão percorrendo nada, eles estão parados. Se fosse fora do cone aí eles vão ter velocidades iguais. No cone é diferente daquele círculo (questão 2). Por causa que (faz um cone de papel) eles (os pontos marcados sobre o cone de papel) não vão percorrer o cone. Se você marcar, se girar, eles vão sempre estar aqui nesta parte do cone (a velocidade relativa dos pontos ao cone é nula, pois fazem parte do corpo do cone).

O problema aqui do sistema de referência é essencialmente resultado da dificuldade de Evandro e Cássio conjugarem a intuição da velocidade global com o conceito de velocidade linear, criando, com isso, um raciocínio inconsistente, devido à imperícia na adoção consciente do referencial do movimento. Os referidos estudantes alternam os seus pensamentos entre dois referenciais, para argumentar acerca da comparação das velocidades dos pontos $\mathrm{A}$ e $\mathrm{B}$, que consideram iguais, no cone ou no CD. Para chegar a isso, adota-se num instante o referencial na Terra, implícito nos problemas, como se vê, por exemplo, em Evandro que percebe que o ponto B "[...] percorre um espaço maior que o $A[\ldots]$ ", ou quando fala que "É o cone que tá girando" ou é "o $C D$ que roda" ou, ainda, quando expressa que "Eles (os pontos A e B) vão rodar [... ]". Noutro instante, preso à intuição da velocidade global, utiliza-se do referencial girante junto ao cone e ao CD para concluir a igualdade das velocidades, pois, como comenta também Evandro: “ $A(\mathrm{~s})$ velocidade(s)[...] são iguais[...] é a mesma (velocidade)". “[...] os dois pontos (A e B) tão parado[...] vão rodar sempre no mesmo lugar . A incoerência dessas afirmações é explicita, pois o aluno viola a importância do espaço maior percorrido pelo ponto $B$, entendendo que as velocidades são iguais, porque, o que importa, é a velocidade única do cone, pensado como um objeto único, e não as suas possíveis partes individuais, assegurando, desse jeito, a intuição da velocidade global. A mesma análise se estende a Cássio que emprega um raciocínio similar, posto que admite o movimento do cone (" $O$ que vai mexer é o cone”), mas não o dos seus pontos 
(" [...] se for fixar no cone, eles estão parados. Eles não tão percorrendo nada[...] eles não vão percorrer o cone[...] eles vão sempre estar aqui nesta parte do cone").

Em suma, a alternância de referencial é clara e de fato existe nas falas dos dois alunos exemplificados, e isso leva à indicação de que os pontos têm velocidades e ao mesmo tempo estão parados. A alternância surge para salvaguardar o ponto de vista da concepção velocidade global que, aparentemente, entra em conflito com o entendimento do conceito de velocidade aprendido, visto que a maior velocidade de B está dada pelo seu maior percurso. Dizemos, aparentemente, de um ponto de vista do "expert", pois, do ponto de vista do aluno, a concepção velocidade global subjuga o conceito de velocidade aprendido, pondo-o de lado, priorizando a velocidade global do cone, que é uma só, e não a diferença dos espaços percorridos dos pontos.

\section{Considerações finais}

Este estudo procurou mostrar como certas concepções alternativas aparecem e se tornam condutoras das mais variadas interpretações, quando alunos são defrontados com certos tipos de problemas. Apesar de adequadamente aplicado em problemas comuns de cinemática, vimos que o conhecimento prévio a respeito de velocidade é insuficiente, quando se trata de analisar o corpo rígido em rotação. Nesse caso, muitos estudantes renunciam àquele conhecimento e priorizam um conjunto de interpretações lastreadas em concepções intuitivas.

Apesar das concepções alternativas aqui descritas já serem bem conhecidas na literatura da área de educação científica, acredita-se que se avançou em dois pontos. O primeiro, na identificação de uma forte tendência para manifestação dessas concepções na situação do corpo rígido em rotação. O segundo, e o principal, ao reconhecer as variadas explicações empregadas pelos estudantes que essas concepções desencadeiam.
Este trabalho deixa, como contribuição, a sugestão do uso de problemas envolvendo corpos rígidos em rotação, após os alunos estarem dominando o conceito de velocidade em problemas mais convencionais, como de pontos materiais ou móveis isolados, durante o estudo da cinemática. Por esta investigação, ficamos convencidos que as dificuldades junto aos aprendizes, geradas por problemas semelhantes aos que foram aqui propostos, e suas ultrapassagens, por mediação do professor, será fundamental, não só para promover uma aprendizagem mais significativa em relação ao conceito de velocidade, mas também para oportunizar uma conexão para a introdução da dinâmica, em cujos objetivos deveria estar presente o enfraquecimento da robusta concepção da força proporcional à velocidade.

\section{Referências}

CARMICHAEL, P. et al. Research on students' conceptions in science: a bibliography. Leeds: University of Leeds, 1990.

DION, S. M. Vetor velocidade angular: um estudo de aspectos tridimensionais envolvidos em sua conceituação. 1992. Dissertação (Mestrado) - Instituto de Física e Faculdade de Educação, Universidade de São Paulo, São Paulo, 1992.

GILBERT, J. K.; SWIFT, D. J. Towards a lakatosian analysis of the piagetian and alternative conceptions research programs, Science Education, New York, v.69, n5, p.681696, 1985.

LABORDE, C. (1996). Duas utilizações complementares da dimensão social nas situações de aprendizado da matemática. In: Garnier, C. et al (Eds). Após Vygotsky e Piaget. Perspectivas social e construtivista. Escolas russa e ocidental. Porto Alegre: Artes Médicas, 1996. p. 29- 46.

PFUNDT, H ; DUIT, R. Bibliography - Student's Alternative Framework and Science Education. Kiel: IPN, 1991.

SILVA, D. O ensino construtivista da velocidade angular. São Paulo: Faculdade de Educação, Universidade de São Paulo, 1990. (Textos Pesquisa para o Ensino de Ciências, $\left.\mathrm{n}^{\circ} 4\right)$.

VIENNOT, L. Spontaneous reasoning in elementary dynamics. European Journal of Science Education, London, v.1, p. 205-221, 1979. 


\section{ANEXO-QUESTIONÁRIO}

QUESTÃO 1 - Dois pontos A e B são desenhados na superfície de um CD de música, conforme a figura. Quando este CD possui uma rotação, pode-se dizer que:

a) a velocidade de A é igual a de B?

b) a velocidade de A é maior do que a de B?

c) a velocidade de A é menor do que a de B?

QUESTÃO 2 - Dois carros A e B estão em duas pistas concêntricas (circulares). Eles percorrem as suas trajetórias (pistas) lado a lado um do outro. Pode-se dizer que:

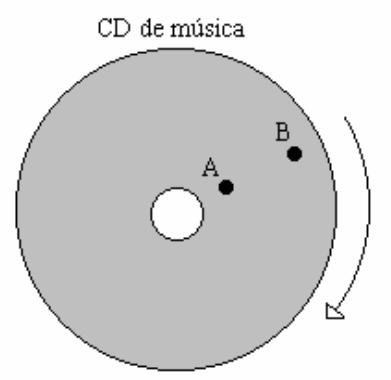

a) a velocidade de Aé igual a de B?

b) a velocidade de A é maior do que a de B?

c) a velocidade de A é menor do que a de B?

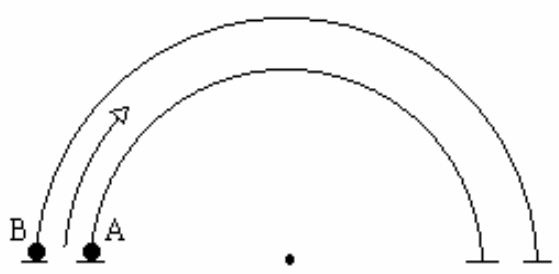

QUESTÃO 3 - Dado um cone que gira sobre seu eixo de simetria, tendo dois pontos A e B desenhados sobre o mesmo, ode-se dizer que:
a) a velocidade de A é igual a de B?
b) a velocidade de A é maior do que a de B?
c) a velocidade de A é menor do que a de B?

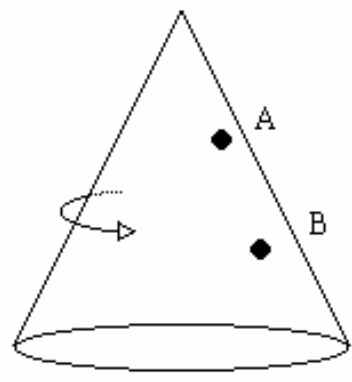

QUESTÃO 4 - Dadas duas roldanas que giram devido a uma correia que apresenta dois pontos A e B. Pode-se dizer que:

a) a velocidade de Aé igual a de B?

b) a velocidade de A é maior do que a de B?a velocidade de A é menor do que a de B?

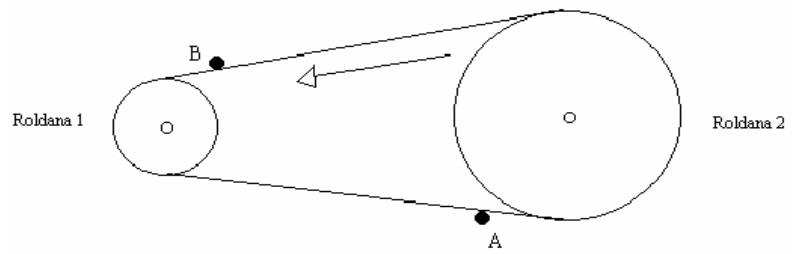

